\title{
A Numerical Proof of Concept for Thermal Flow Control
}

\author{
Valeriu Dragan \\ Computational Fluid Dynamics Department \\ National Research and Development Institute for Gas Turbines, COMOTI \\ Bucharest, Romania \\ drvaleriu@gmail.com, valeriu.dragan@comoti.ro
}

\begin{abstract}
In this paper computational fluid dynamics is used to provide a proof of concept for controlled flow separation using thermal wall interactions with the velocity boundary layer. A 3D case study is presented, using a transition modeling Shear Stress Transport turbulence model. The highly loaded single slot flap airfoil was chosen to be representative for a light aircraft and the flow conditions were modeled after a typical landing speed. In the baseline case, adiabatic walls were considered while in the separation control case, the top surface of the flaps was heated to $500 \mathrm{~K}$. This heating lead to flow separation on the flaps and a significant alteration of the flow pattern across all the elements of the wing. The findings indicate that this control method has potential, with implications in both aeronautical as well as sports and civil engineering applications.
\end{abstract} device

Keywords-heat transfer; CFD simulation; flow control; high lift

\section{INTRODUCTION}

Controlling flow attachment on aerodynamic surfaces is one of the main engineering subjects of recent years. From aircraft wings [1] or thrust vectoring [2] to both radial [3] or axial [4] flow turbomachinery and even synthetic jets in sports vehicles [5] and buildings [6], having the ability to control boundary layer separation opens new possibilities for design and operation. This paper deals with a theoretical concept for flow control which has been tested, using state of the art CFD methods, with advanced turbulence modeling. In [7], a multitude of traditional flow control methods is described and commented. Thin wall jets have been used for circulation control as well as supercirculation [8]. Additionally, more recent development of piezo-electric [9] actuators, unsteady passive actuation [10] or even plasma actuators [11] have made their way to high technology readiness levels, providing viable alternatives for aerodynamicists in various fields of engineering.

Conventionally, heating was used on aircraft wings to reduce the Reynolds number near the wall of the wing in order to diminish turbulent friction. Indeed the theoretical background this technique is rooted in provides an optimal point in which virtually all flow near the wall is essentially laminar. However, the power consumption associated with the heating as well as the advent of natural laminar airfoils [12] has made this all but useless for airline applications. Smaller aircraft and drones have been fitted with similar technologies in the same traditional sense. Due to their small characteristic length, UAV propellers have been shown to be positively influenced by surface heating [13]. As far back as the 1980's, the prospect of using heated airfoils for improved aerodynamic performances was explored [14]. The typical applications rely on the lowering of the Reynolds number through the local increase in fluid viscosity as the result of heating. In this way, the friction coefficient becomes a function of temperature.

However, in the proposed embodiment of this method, a spoiler-like behavior is sought without the need for geometry variations. Such a method could be used for small aerial vehicles for both rolling maneuvers and landing, without the requirement for complex and heavy moving parts, thus increasing reliability and reducing overall weight.

$$
\begin{gathered}
\tau_{w}=\left.\mu \frac{\partial u}{\partial y}\right|_{y=0} \\
\mu=\mu_{0}\left(\frac{T}{T_{0}}\right)^{3 / 2} \frac{T_{0}+S}{T+S} \\
\operatorname{Re}=\frac{\rho \cdot v_{\infty} C}{\mu}
\end{gathered}
$$

A previous study confirmed that, for airfoils with low camber and viscous dominated drag, a careful distribution of wall temperature can lead to a serious reduction in the drag coefficient as well as a marginal increase in lift coefficient [15].

\section{COMPUTATIONAL FLUID DYNAMICS CASE SETUP}

The current paper uses state the of the art k-omega SST RANS model, with additional equations for compensating the laminar to turbulent transition and curvature correction to obtain a proof of concept case for the use of thermal actuation for boundary layer separation. A highly loaded airfoil was considered, with typical single-slot flaps and gurney type element on the trailing edge. In the baseline case adiabatic noslip walls were used whereas in the thermal trimming case, the top surface of the flaps was set to a uniform surface temperature of $500 \mathrm{~K}$. Surface roughness was considered null, bearing in mind that the rugosity itself will (in a real life application) promote the mixing of the turbulent boundary 
layer and therefore increase the heat transfer. The geometry of the airfoil and flaps was constructed using an Eppler S1223 for the main airfoil and flaps with a $10 \mathrm{~mm}$ gap between the two and a combined chord of $300 \mathrm{~mm}$. The setting angle of attack for the main airfoil is $0^{\circ}$ and the flaps is set at $40^{\circ}$. This airfoil has been chosen due to its high loading and low drag [16].

Since this is a preliminary study, seeking an additional validation of the theoretical principle behind the separation control, the CFD study was conducted using RANS methods. Having said this, the case presents a 3D domain - albeit with periodic conditions - while the turbulence model was chosen in such a way that transition from laminar to turbulent - as well as relaminarisation could be theoretically captured. Furthermore, grid sensitivity tests were performed on three grids with increasing cell density (i.e. baseline, baseline $\mathrm{x} 2^{3}$, baseline $\mathrm{x} 2^{6}$ ). The current mesh was the result of the analysis of the trends of the three grids with respect to lift, drag and moment coefficient. Another relevant aspect is that the first cell (nearest to the wall) was kept constant for all four cases, insuring the same $y+$ for every case. The fluid considered was the classical RedlichKwong which has a built in wall temperature correlation. Figures 1 and 2 depict the blocking structure, near wall cell distribution and the $\mathrm{y}+$ distribution for both presented cases.
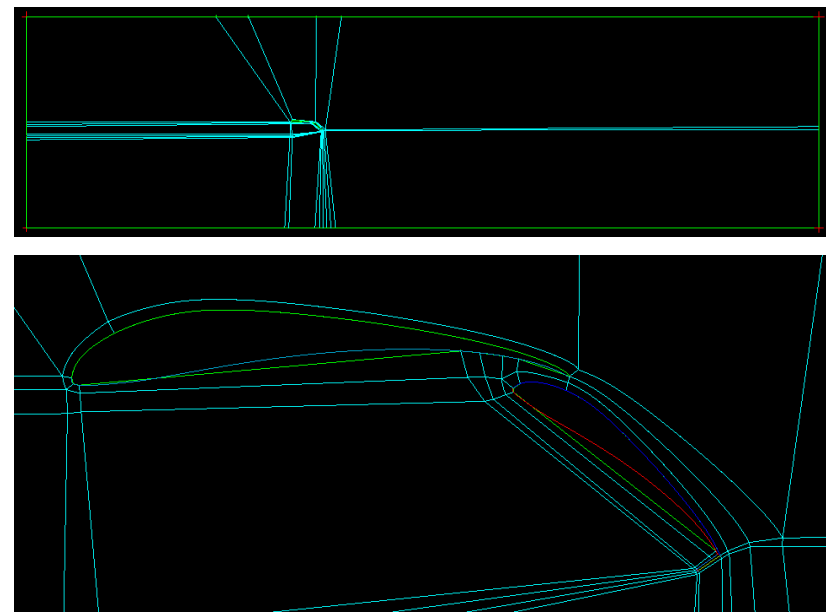

Fig. 1. Blocking structure for the adiabatic and heated cases

As stated, the turbulence model employed was the transition SST-RC k-omega [17], as implemented in Ansys Fluent v17. As seen, the near wall mesh meets the criteria $y^{+}$ for k-omega models, in particular for the one used. Since the Reynolds number is expected to decrease with temperature, the cell size used in the adiabatic case was considered - and proven - to be sufficiently small to also cover the heat transfer case. The method used to calculate the first cell size was through the equation below [18] where $h$ is the first cell height, $v$ is the kinematic viscosity and $\tau_{w}$ is the wall shear stress.

$$
h=\frac{\tau_{w} y^{+}}{\nu}
$$

One of the key elements of the heat transfer simulation is the interaction between the velocity boundary layer with the thermal boundary layer. Multiple tests have been reported in the literature, concluding that the SST [19] and SA [20], which both model the boundary layer without wall functions, are best suited for the heat transfer [21].

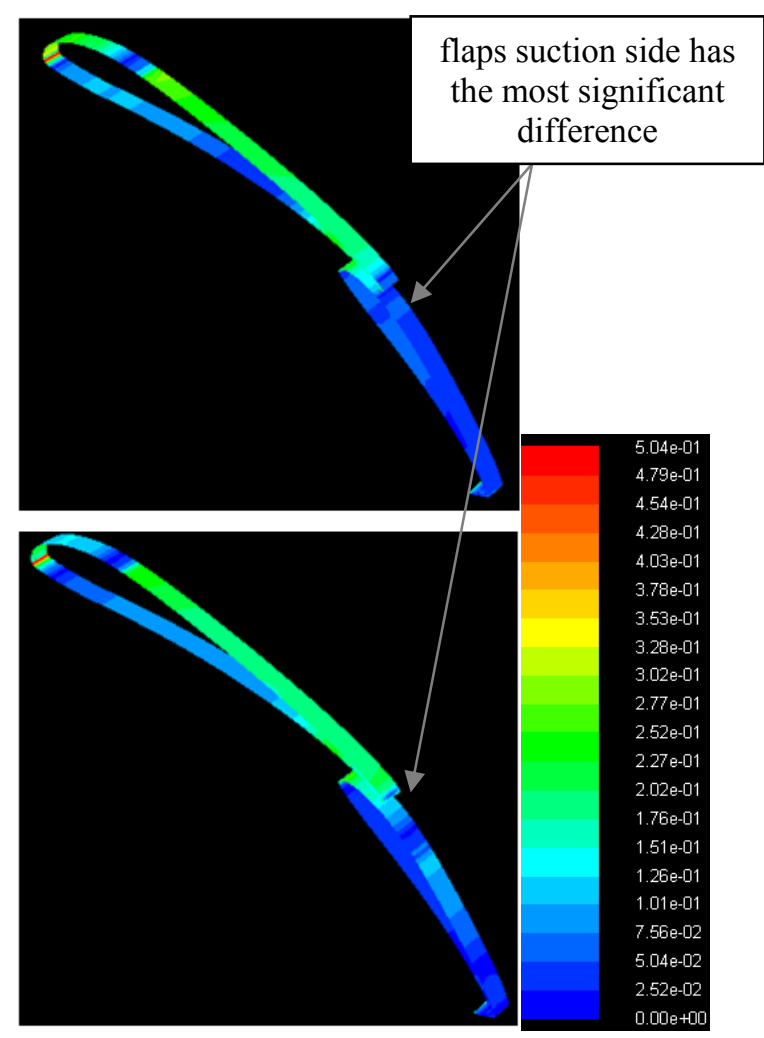

Fig. 2. The $\mathrm{y}+$ distribution for the adiabatic and heated cases

In terms of boundary conditions, the solid surfaces were considered smooth walls, with no slip condition, the sides of the domain were considered periodical and the velocity inlet was set along the Ox axis at a magnitude of $50 \mathrm{~m} / \mathrm{s}$ with an ISA atmosphere as a reference. The CFL condition was set to a value of one unit, in order to correctly capture the physical phenomena of heat convection through the boundary layer.

\section{RESULTS AND DISCUSSIONS}

As is the case with all flapped airfoils, the increase in the overall lift coefficient is owed to the change of pressure distribution around the main airfoil as a result of the secondary airfoil (flaps) disturbance in the flow. By shifting the leading edge stagnation point, the flaps makes to airfoil behave as if the angle of attack had been increased, but without the danger of destabilizing the flow on the top of the main foil. The shift of the LE stagnation point has two main components, the first of which being the deceleration on the underside of the foil, the second reason is more subtle and has to do with the interaction with the flow on top of the flaps itself. Since the flow on the top of the flaps acts similarly to a curved wall jet, the entrainment effects on the flow circulating on the top of the main foil contributes to the apparent increase in angle of attack. In the heated version however, this entrainment occurs to a 
significantly lesser degree, meaning that its contribution to this apparent AoA increase will be negligible.

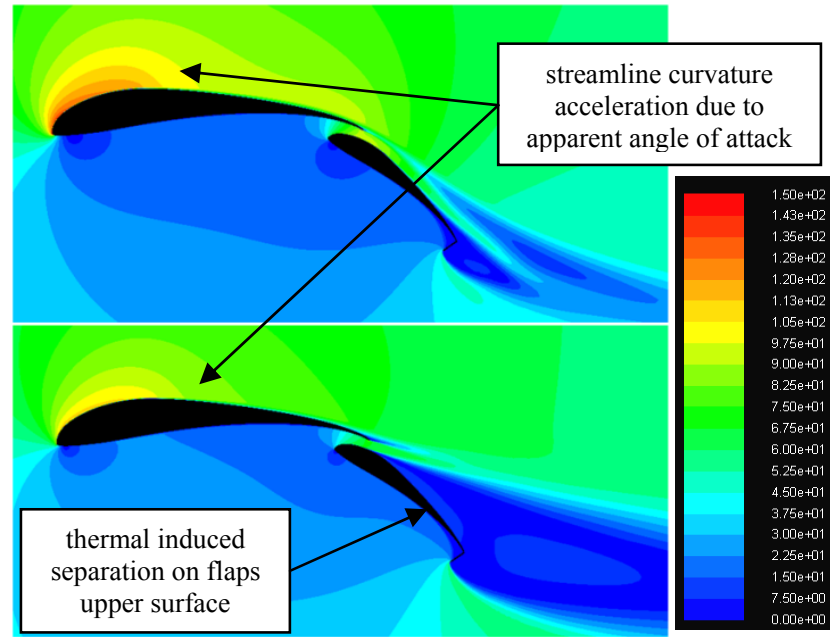

Fig. 3. Velocity magnitude field in the midspan section without (top) and with flow thermal-induced flow separation (bottom)

Figure 3 provides an interesting behavior (particular to this type of flow control) in which the flaps no longer manages to perturb the flow in the same manner. Notice that, although the underside flow pattern remains virtually the same, the topside flow is significantly different. It is this difference that leads to the differences in lift and drag seen in the figure below. Figures 4-6 shows bar charts of the results.

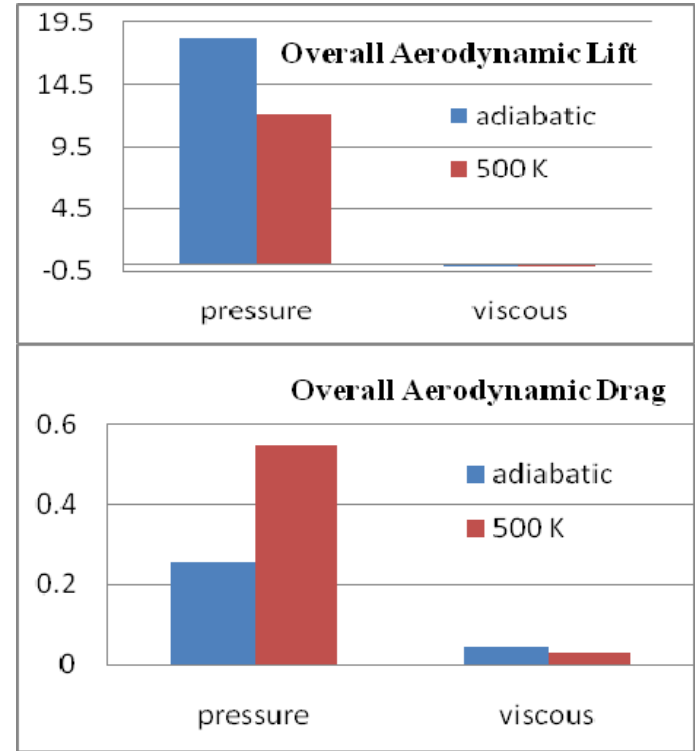

Fig. 4. Overall lift and drag breakdown for the two considered cases

As shown increased drag is experienced by the stalled flaps due to the thermal trimming is in fact the result of a double influence. Equally the positive flaps drag is increased whereas the negative drag of the main airfoil is decreased. It must be said that the negative drag on the main foil arises due to the pseudo-incidence that the flaps induces. This negative drag is always going to be canceled out and surpassed by the added positive drag of the flaps, even if it is not stalled. Unfortunately, in this case, the negative drag component on the main airfoil is inextricably linked to the lift force on the respective section. Therefore, if we pursue the diminishing of the overall lift we will have to accept the diminishing of the negative drag. Hence, the only avenue for further optimization of this arrangement will have to rely on the flaps pressure drag and, to some extent, on the main airfoil skin friction drag perhaps with the classical heating described in [7].

Further, it can be seen that both the main and flap airfoils lead to significant decreases in their respective lift force, to approximately $70 \%$ in the case of the main and $60 \%$ for the flaps. This is due primarily to the diminishing of the circulation on the top side of both the airfoil elements as downstream diffusion is significantly decreased hence impeding the acceleration of the upstream flow. The Gurney element also registers an influence, however it is marginal when viewed only on the element itself.

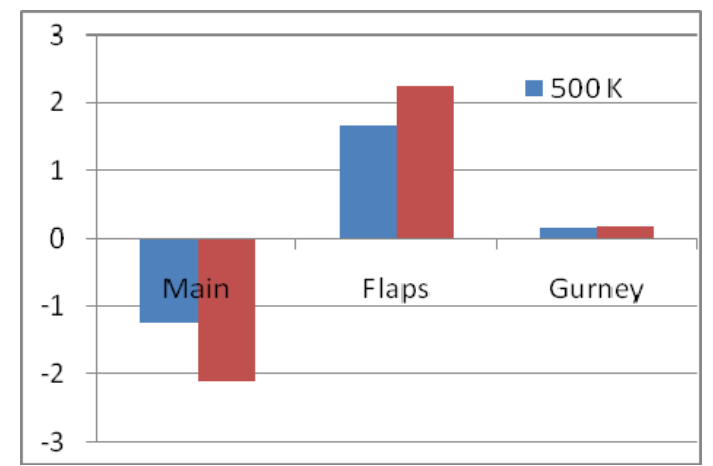

Fig. 5. Drag force breakdown for the two cases

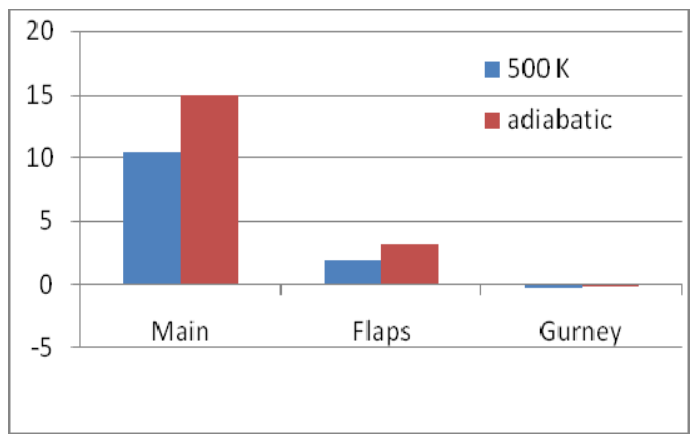

Fig. 6 - Lift force breakdown on the components

\section{CONCLUSIONS}

The paper deals with the prospect of using skin thermal influences on the velocity boundary layer in order to induce separation, essentially stalling an airfoil which (under normal circumstances) would have no stall tendencies. In our case, a conventional highly loaded airfoil with single slotted flaps was used as a benchmark. The topside of the flaps, when heated, induced boundary layer separation on the flaps which - in turn led to the change of the overall characteristics of the entire assembly. Since the Mach number was low, comparable to 
typical landing speeds of civilian aircraft [22], the influence upstream of the flaps is quite visible on the main foil. A breakdown of aerodynamic forces on the components of the assembly revealed that the lift and drag contribution of the flaps on the overall force is only part of the trimming. By looking at the flow pattern around the main airfoil, we can observe that the velocity distribution corresponds to a state where the flaps would be extended at a lower angle. Although the lift has been successfully reduced by using the proposed method, the drag penalty appears to be (at least in part) linked to it. Hence, the main direction in which the drag can be reduced would be to use the minimization of the pressure drag on top of the flaps though the use of conventional curved wall jets [23]. Although both theoretical [24] and empirical efforts [25] have been made to model the boundary layer velocity distribution on such flows, the addition of a wall temperature as a factor will most certainly require further study and modeling.

\section{REFERENCES}

[1] D. Miklosovic, R. Imber, M. Britt-Crane, "Measurements of Midspan Flow Interactions of a Low-Aspect-Ratio Circulation Control Wing", Journal of Aircraft, Vol. 53, No. 6, pp. 1969-1974, 2016

[2] J. Páscoa, A. Dumas, M. Trancossi, P. Stewart, D. Vucinic, "A review of thrust-vectoring in support of a V/STOL non-moving mechanical propulsion system", Open Engineering, Vol. 3, No. 3, pp. 374-388, 2013

[3] I. Malael, H. Dumitrescu, A. Dumitrache, "Methods for Improve the Performance of the Turbomachines Using the Flow Control", AIP Conf. Proc., Vol. 1389, 2011

[4] M. G. De Giorgi, E. Pescini, F. Marra, A. Ficarella, "Experimental and Numerical Analysis of a Micro Plasma Actuator for Active Flow Control in Turbomachinery", ASME Turbo Expo 2014: Turbine Technical Conference and Exposition, Germany, June 16-20, 2014

[5] M. N. Sudin, M. A. Abdullah, S. A. Shamsudin, F. R. Ramli, M. M. Tahir, "Review of Research on Vehicles Aerodynamic Drag Reduction Methods", International Journal of Mechanical and Mechatronics Engineering, Vol. 14, No. 2, pp. 35-47, 2014

[6] S. J. Kang, J. Park, K. Y. Oh, J. G. Noh, H. Park, "Scheduling-based real time energy flow control strategy for building energy management system", Energy and Buildings, Vol. 75, pp. 239-248, 2014

[7] M. Gad-el-Hak, Flow Control: Passive, Active, and Reactive Flow Management, Cambridge University Press, 2007

[8] V. Ciobaca, J. Wild, "An Overview of Recent DLR Contributions on Active Flow-Separation Control Studies for High-Lift Configurations", Aerospace Lab Journal, Vol. 6, 2013

[9] L. Iorga, H. Baruh, I. Ursu, "Refined Analysis of the Piezoelectric Pseudo-Active Control for Helicopter Blades Vibration", 46th
AIAA/ASME/ASCE/AHS/ASC Structures, Structural Dynamics and Materials Conference, USA, April 18-21, 2005

[10] S. Endrikat, B. Roentsch, J. C. Little, L. Taubert, C. F. de Luzan, E. J. Gutmark, I. J. Wygnanski, "Physics and Control of the Flow over a Generic Trapezoidal Wing Planform", 54th AIAA Aerospace Sciences Meeting, USA, January 5-8, 2016

[11] X. Zhang, H. X. Li, Y. Huang, W. B. Wang, "Wing Flow Separation Control Using Asymmetrical and Symmetrical Plasma Actuator", Journal of Aircraft, 2016

[12] R. W. Barnwell, M. Y. Hussaini, Natural Laminar Flow and Laminar Flow Control, Springer Verlag, 2012

[13] D. A. Kessler, R. Johnson, A. T. Corrigan, S. Qidwai, M. Merrill, J. Thomas, "Modeling low-Reynolds-number flow over rough airfoils", 54th AIAA Aerospace Sciences Meeting, USA, January 5-8, 2016

[14] L. Maestrello, F.F. Badavi, K. W. Noonan, An application of active surface heating for augmenting lift and reducing drag of an airfoil, NASA Technical Memorandum 100563, 1988

[15] V. Dragan, "Influences of surface temperature on a low camber airfoil aerodynamic performances", INCAS Bulletin, Vol. 8, No. 1, pp. 49-60, 2016

[16] M. S. Selig, J. J. Guglielmo, "High-Lift Low Reynolds Number Airfoil Design", Journal of Aircraft, Vol. 34, No. 1, pp. 72-79, 1997

[17] G. Kalitzin, G. Medic, G. Xia, "Improvements to SST turbulence model for free shear layers, turbulent separation and stagnation point anomaly", 54th AIAA Aerospace Sciences Meeting, USA, January 5-8, 2016

[18] F. M. White, Fluid Mechanics, 7th edition, McGraw-Hill, 2009

[19] K. Tsukamoto, Y.Horiuchi, K. Sugimura, S. Higuchi, "Conjugate Heat Transfer Analysis in an Actual Gas Turbine Rotor Blade in Comparison With Pyrometer Data", ASME Turbo Expo 2014: Turbine Technical Conference and Exposition, Germany, June 16-20, 2014

[20] S. Allmaras, F. Johnson, P. Spalart, "Modifications and clarifications for the implementation of the Spalart-Allmaras turbulence model", 7th Internaitonal Conference on Computational Fluid Dynamics ICCFD7, Hawai, July 2012

[21] G. Zigh, J. Solis, Computational Fluid Dynamics Best Practice Guidelines for Dry Cask Applications, NUREG, 2012

[22] M. Janic, "Modeling effects of different air traffic control operational procedures, separation rules, and service disciplines on runway landing capacity", Journal of Advanced Transportation, Vol. 48, No. 6, pp. 556574,2014

[23] M. Burnazzi, R. Radespiel, "Synergies between suction and blowing for active high-lift flaps", CEAS Aeronautical Journal, Vol. 6, No. 2, pp 305-318, 2015

[24] M. Trancossi, A. Dumas, D. Vucinic, "Mathematical Modeling of Coanda Effect", SAE Technical Paper No. 2013-01-2195, 2013

[25] V. Dragan, "Implementation of a correction factor for the Pohlhausen laminar boundary layer applied on the CEVA curved wall jet model", INCAS Bulletin, Vol. 5, No.3, pp. 61-67, 2013 